\title{
La Torre del Homenaje de la alcazaba de Loja (Granada)
}

\author{
The Tower Keep of the alcazaba at Loja (Granada)
}

\author{
Samuel Márquez Bueno * \\ Pedro Gurriarán Daza ***
}

\begin{abstract}
RESUMEN
En las próximas líneas se realiza un breve análisis sobre las características formales y constructivas de la Torre del Homenaje de la alcazaba de Loja. Se trata de una interesante obra defensiva construida a caballo entre el ocaso del mundo almohade y el nacimiento del nuevo poder nazarí. Como consecuencia, esta torre será reflejo de la arquitectura de ambas épocas, siendo un verdadero crisol en el que se advierten aspectos singulares de las puertas de tipo monumental que conocemos de ambos periodos.
\end{abstract}

Palabras clave: Torre del Homenaje, alcazaba, epigrafía, almohade, nazarí

\section{INTRODUCCIÓN}

De entre todos los vestigios de época andalusí subsistentes en el interior del recinto de la alcazaba de Loja se podrían destacar, por su monumentalidad, el aljibe y la llamada Torre del Homenaje. Paradójicamente, el interés suscitado por cada uno de ellos no se corresponde con su importancia medida en términos de singularidad, funcionalidad y valor simbólico; de este modo, la obra más significativa de la alcazaba ha sido la menos atendida por los investigadores y estudiosos de la arquitectura defensiva andalusí. Con este breve artículo pretendemos hacer un primer análisis de la Torre del Homenaje, recien-

\begin{abstract}
In the following lines we carry out a brief analysis of the formal as well as designing characteristics of the Tower Keep of the alcazaba of Loja. It is an interesting defensive construction built between the decline of the almohad world and the beginning of the new nasrid power. As a result, the tower was the reflection of the architecture of both times, becoming a melting pot in which we can find singular aspects of all the monumental gates that we have knowledge of from both periods.
\end{abstract}

Key words: Tower Keep, citadel, epigraphy, almohad, nasrid temente restaurada, incidiendo en sus aspectos arquitectónicos primigenios y considerando algunas hipótesis a propósito de su origen. Lo acompaña un levantamiento fotogramétrico realizado por los autores, así como diversos esquemas de su estructura general.

Su denominación tradicional sobrepasa el modelo habitual asociado a este tipo de obras defensivas. Se trata de una construcción singular, difícil de clasificar con precisión, ya que el uso residencial queda condicionado por la gran sala abovedada abierta en planta baja tras un arco monumental. Es complicado, por tanto, encasillar esta obra, e incluso el término de Calahorra,

* Yamur. Arquitectura y Arqueología S.L.

*** Instituto de Estudios Campogibraltareños. 
quizás el más adecuado dadas sus características generales ', no termina de coincidir con las peculiaridades estudiadas. En cualquier caso, dado su arraigo, mantendremos la denominación tradicional a lo largo del discurso en aras de no crear confusión.

\section{DESCRIPCIÓN ARQUITECTÓNICA Y CONSTRUCTIVA}

El monumento objeto de estudio se sitúa en el recinto alto o alcazaba de la ciudad de Loja, población de tamaño medio situada a poniente de la actual provincia de Granada, donde actuaba como llave de entrada a la Vega y controlaba un amplio territorio en época nazarí. En efecto, en ese momento, Loja era un importante enclave urbano, cabeza de una unidad político-administrativa (IIMÉNEZ PUERTAS, 1995). La alcazaba ocupaba una posición nuclear, y como suele ser habitual en este tipo de construcciones, basaba su fundamento defensivo en su ubicación alta y enriscada, dominando los restantes recintos urbanos 2 . La fortaleza se yergue sobre un promontorio calizo, justo al pie de Sierra Gorda; dos fuertes tajos la mantienen inaccesible por el norte y el sur. En 1486, fecha de la conquista castellana, la organización urbana quedaba completada por el barrio del Jaufín, al norte, y el Arrabal a mediodía, ambos amurallados (JIMÉNEZ PUERTAS, 1995, p .63).

En la actualidad la Torre del Homenaje se conserva adosada y comunicada con la Casa de los Alcaides Cristianos (S. XVII), aunque no está integrada en ningún circuito amurallado (Fig. I). Hemos de tener en cuenta que esta construcción había llegado a nuestros días parcialmente destruida, con reformas y transformaciones en su volumetría, circunstancia que motivó su puesta en valor hace apenas un par de años (Fig. 2 y Lám. I). En su origen sería una edificación exenta, de gran porte, que debió de contar con varias plantas de las que sólo se conserva la inferior ${ }^{3}$. En ella se ubica una sala de planta cuadrada cubierta por una elevada cúpula, flanqueada por dos alcobas, y a la que se accede a través de la puerta señera abierta en el frente este (Fig.3) ${ }^{4}$. En los niveles superiores de la torre debieron de emplazarse una serie de estancias desaparecidas, cuyo acceso se realizaría a través de una escalera que arrancaría desde la alcoba meridional.

En cualquier caso, y atendiendo a criterios de conservación de la obra original y relevancia simbólica y funcional, centraremos nuestro estudio en la sala con cúpula y, sobre todo, en la portada monumental.

Ésta última se ubica en el fondo de un gran vano abierto en el centro de la cara oriental de la torre, y a la que es paralela. En sus cercanías se han edificado viviendas, tan próximas que dificultan la visión actual de la portada con la suficiente perspectiva. Como complemento defensivo cuenta con una buhedera situada, junto a la fachada, en la clave de la bóveda de cañón que acota el espacio previo a la referida fachada. Su alzado, rectangular en su parte inferior y semicircular en la superior, está dominado por un arco enjarjado de herradura aguda ligeramente rehundido respecto del alfiz que lo enmarca. Las albanegas estaban decoradas con motivos de ataurique, ocultos hasta la última intervención restauradora en la que se han limpiado y consolidado los fragmentos subsistentes (Lám. 2). Por lo que respecta al

\footnotetext{
I Se trataría de una torre prominente dentro de las defensas urbanas, generalmente asociada a las alcazabas, o incluso puentes, como vemos en el Puente Mayor de Córdoba. Si bien es difícil vincularlas a alguna época concreta, proliferan sobre todo en periodo bajomedieval, como vemos en las alcazabas de Gibraltar, Antequera o la propia Alhambra, por citar algunos ejemplos. (TORRES BALBÁS, 1942, p. 192, nota 2. TORRES BALBÁS, 1985, pp. 497 y 498)

2 Sobre las defensas de Loja, a modo de exhaustiva descripción, véase MALPICA CUELLO, 1996, pp. 215 y 216.

3 Esta construcción aparece exenta en el grabado del Civitates Orbis Terrarum, de mediados del siglo XV. En él la torre presenta su fachada norte parcialmente destruida, además de la cubierta desaparecida.

4 Hasta hace escasas fechas el acceso se realizaba mediante un vano practicado en el frente norte, como resultado de una transformación moderna en la que se prescindió de la puerta original. (MALPICA CUELLO, 1996, p. 215). En las últimas obras de puesta en valor se ha recuperado la solución primitiva de acceso a la sala abovedada.
} 
trazado geométrico, el arco está generado por dos circunferencias levemente desplazadas, y un alfiz perfectamente cuadrado cuya base coincide con la línea inferior de la impostas y a cuyo centro se dirigen las líneas de despiece del arco (Fig. 4).

Por encima del alfiz, prácticamente en la transición entre los mencionados sectores rectangular y semicircular, y ocupando la amplitud de la fachada, se ubica una banda epigráfica cuyo tramo central derecho ha desaparecido, posiblemente por efecto de algún seísmo que desplazó levemente hacia el exterior los dos sillares situados inmediatamente por debajo y que limitan con el alfiz. Finalmente, sobre la parte central de la inscripción se emplaza la representación de una llave con cordón y borla (Lám. 3). Este epígrafe está ejecutado en yeso, con letras y decoración en relieve, dispuesto sobre una base de ladrillos visible antes de la última restauración. La silueta de la llave está retallada sobre un sillar y el rebaje resultante relleno con fragmentos de ladrillo $y$ mortero ${ }^{5}$.

Por otra parte, la sala con cúpula es un espacio de planta cuadrada, como ya se ha referido, cubierto por una elevada bóveda esquifada de ocho paños, sustentada por trompas de aristas, en cuyo arranque se sitúan unas granadas y racimos frutales de piedra (Láms. 4 y 5). Cada uno de los paños mencionados está decorado con un motivo de entrelazo (sebka) ejecutado con ladrillo, aunque actualmente sólo es visible tal ornato en un par de paños que no han sido enlucidos de nuevo (Lám. 6).

En cuanto a la ejecución material, todo el alzado de la portada está aparejado en sillería de cuidada labra, con algunos engatillados y juntas finísimas; lo que denota que no se han empleado piezas de acarreo y que la obra es realizada en un único impulso constructivo por un mismo grupo de canteros. Además, sus sillares forman unidad con los de los paramentos aledaños, incidiendo en el sincronismo general de la primitiva construcción andalusí ${ }^{6}$. A partir de los siete metros de altura la obra original de sillería presenta abundantes apaños, fruto de restauraciones posteriores. Por ejemplo, en el frente oriental vemos mamposterías sobre las que se alzan sillares posiblemente de acarreo; tres mensuras de piedra son el posible testigo de un balcón añadido junto a estas fábricas. En la cara norte, las reparaciones en la parte alta de la torre se repiten, quizás con mayor volumen. Estas alteraciones se deben relacionar con arreglos modernos, pues hemos comentado en la nota 6 cómo en el grabado del Civitates Orbis Terrarum la torre tiene su alzado septentrional y la cubierta arruinados.

En cualquier caso, hay que hacer constar la singularidad de la edilicia original de esta torre dentro del contexto general de las defensas andalusíes de Loja, en las que priman las técnicas de albañil (mamposterías y tapias) sobre las de cantero ${ }^{7}$. Su especificidad y calidad constructiva hablan del carácter especial y destacado de la construcción, y puede permitirnos pensar en un encargo puntual ejecutado por alarifes o canteros alóctonos.

En general, se puede identificar en el recinto de la alcazaba una primera obra defensiva de tapia de hormigón de cal (tabiya), que delimitaría el actual perímetro del recinto alto. Es difícil platear cronologías más o menos exactas a partir de las características modulares o com-

5 Conviene aclarar, cara al desarrollo argumental de este artículo, la evidente unidad constructiva en sentido cronológico que presentan todos los elementos integrantes de esta fachada monumental.

6 Está en proceso de ejecución un estudio de paramentos sistemático de la construcción, cuyas conclusiones podemos avanzar. Si bien se observa una gran homogeneidad en los paramentos de la torre original, localizamos algunos cambios puntuales en el aparejado de la cantería: así, vemos algunas piezas dispuestas a soga y tizón en las hiladas inferiores del frente norte. En cualquier caso, es difícil asegurar que la parte inferior de la torre sea anterior a la obra principal, a pesar del ligero cambio de aparejo. De este modo, discrepamos con otras tesis que sitúan su origen, por este motivo, en pleno período omeya. SÁNCHEZ MARTíNEZ et alli, I994, p. 24. Téngase en cuenta, por ejemplo, que la Puerta del Capitel de Badajoz presenta parte de su cantería aparejada a soga y tizón y no deja de ser una obra monofásica almohade.

7 Léase sobre estas cuestiones, de forma general, QUIRÓS CASTILLO, 1998, pp. 235 a 246. 
positivas de esas tapias, no obstante, sí debemos llamar la atención sobre la similitud que observamos con aquellas construidas en periodo almorávide-almohade en el sur peninsular y el Algarve portugués ${ }^{8}$. Se trata de materiales con abundancia de arena y cal, generalmente muy finos en su granulometría.

La presencia de estas tapias de hormigón en toda la longitud del frente norte, así como en el resto del trazado sur de la alcazaba, nos permite suponer que la formalización de este recinto alto ya estaba realizado en algún momento comprendido entre mediados del siglo Xll y las dos primeras décadas del siglo XIII. En cualquier caso, creemos que esta muralla ya estaría en pie cuando el enclave es violentamente asaltado en 1225 por Fernando III y su aliado, el señor de Baeza 'Abd Allah al-Bayasí, ocasión que las crónicas describen haciendo mención a que "los habitantes se protegieron detrás de sus sólidas murallas" (AL-HIMYARI, 1938, pp. 76 y 77). Esta obra almohade no sólo empleó la técnica constructiva más difundida en sus promociones militares, sino que incluso manifestó un cierto afán propagandista tal y como vemos en la construcción de dos torres poligonales de ángulo, la Ochavada en el espolón de poniente, y la desaparecida del extremo oriental conocida como de Basurto (SÁNCHEZ MARTÍNEZ, 1994, p. 26).

El segundo punto de interés en la evolución de esta muralla de la alcazaba se da en periodo nazarí, cuando la obra de tapia es forrada y reforzada en su conjunto mediante mamposterías enripiadas. La ejecución de estas fábricas tan características nos permite relacionarlas con una actuación general de restauración de recintos fronterizos del Reino Nazarí. En efec- to, algunas investigaciones vinculan la noticia ofrecida por lbn al-Jatib, sobre la reparación de veintidós fortalezas por parte de Muhammad $V$, entre ellas El Burgo o Archidona, con esa forma de construir tan particular. El análisis de otras fortalezas como Moclín, Antequera, Grazalema o Comares, por ejemplo, permite hablar de un grupo de obras construidas con la misma técnica y ejecutadas en tiempos de MuhammadV (ACIÉN ALMANSA, 1999b pp. 427 a 438). En todas ellas las estructuras se resuelven con mampuesto mediano, cuidando hiladas, y con abundante enripiado. En general, esta actuación estatal incluye la erección de torres de planta semicircular peraltada, circunstancia que se da en el caso de Loja. El sillarejo se usa para resolver los ángulos de torres poligonales, como ocurre con la Ochavada. Detrás de una actuación tan representativa, sobresale el interés estatal en dejar su impronta mediante una forma de construir reconocible ${ }^{9}$, con una clara intención de plasmar, a través de la edilicia, un mensaje de la autoridad que la promueve ${ }^{10}$.

\section{EN EL OCASO ALMOHADE}

La arabista María Antonia Martínez Núñez, en un artículo ya clásico, adjudica a la portada objeto de estudio una cronología que sitúa su erección en torno a los últimos años del período almohade, basándose en las características formales de la inscripción y en su contenido (MARTíNEZ NÚÑ̃EZ, 1997, p. 427. MARTíNEZ NÚÑEZ, 2005, pp. 12 y 13). Se trata de la sura II2 del Corán, que hace alusión a la unicidad de Allah. En el caso de Loja, la banda epigráfica carece de basmala introductoria, por lo que la trascripción sería: qul huwa allahu áhad / Al[lahu as-sámad I lam yálid wa lam yulad I wa] lam yákun la hu

8 Suelen predominar en los grandes recintos de tapia construidos en el entorno del valle del Guadalquivir, así como en el conjunto del Garb al-Andalus. Sobre estos hormigones, consúltense GURRIARÁN DAZA, P., 2000, pp. I I 0 a I I 3, y GURRIARÁN DAZA, SÁEZ RODRÍGUEZ, A. .., 2002, pp. 603 a 6 I4. Asimismo, AZUAR RUIZ, 2005, pp. 123 a I47; del mismo autor, AZUAR RUIZ, 2004, pp. 57 a 74.

9 Acién Almansa destaca la aparición de torres de planta semicircular, macizas y aparejadas con mamposterías enripiadas como un tipo de intervención emblemática estatal. ACIÉN ALMANSA, 1995, p. 34.

10 También hemos de hacer notar que la práctica de forrar con fábricas pétreas los hormigones es común en numerosas fortificaciones de frontera nazaríes, tal vez con la intención de reforzar las estructuras ante la amenaza de la pirobalística. Destaquemos así los forros vistos en los castillos de Píñar, Moclín o la alcazaba de Antequera, además de las reparaciones estudiadas en los recintos de Zagra o illora. MALPICA CUELLO, 1998, p. 288. 
kufúan áhad ", cuya traducción sería: Di: Él es Allah, el Único/Allah, el Eterno/ no ha engendrado ni ha sido engendradol y no tiene asociados. La toma y arrasamiento de Loja en 1225, por las huestes de Fernando III, ya comentada, podría reforzar semejante adscripción cronológica, suponiendo una rápida reconstrucción de las defensas inmediatamente después, en la que se podría encuadrar esta obra.

En cualquier caso, dado el posible carácter hiperbólico de las fuentes sobre el alcance de la destrucción, y teniendo en cuenta los escasos datos arqueológicos relacionados con la Torre del Homenaje 12, preferimos basar nuestro discurso sobre la datación en un análisis arquitectónico y formal que la ponga en contexto dentro de la poliorcética almohade; teniendo siempre presente que el principal argumento en ese sentido es el que ya ha ofrecido la mencionada arabista. Por tanto, hay que tener presente que nuestra sistemática no es concluyente sin nueva información arqueológica, tanto de subsuelo como de paramentos, de modo que cualquier hipótesis se ha de considerar como mero punto de partida en un análisis más completo que concluirá con nuevos datos en un futuro.

Durante el período almohade se constatan radicales diferencias, en la concepción de las puertas militares de recintos urbanos y alcazabas, a uno y otro lado del Estrecho (MÁRQUEZ, GURRIARÁN, 2008, pp. 1 I 5 a I34). De modo general podemos apreciar que, mientras que en el norte de África la composición de las portadas está dominada por varios arcos doblados, de herradura, lobulados, y de medio punto; en torno a los que se articulan sus motivos ornamentales: geométricos, vegetales, y epigráficos; en la península lbérica el modelo, cuya presencia se constata de forma sistemática, muestra un esquema compositivo más sencillo regido por un arco de herradura, a menudo ligeramente apuntado, y rehundido respecto del omnipresente alfiz ${ }^{13}$. En cuanto a la decoración, es inexistente en la superficie de la portada inmediata al vano ${ }^{14}$, ubicándose los escasos elementos ornamentales a modo de fajas situadas en la parte superior, como atestiguan las fortificaciones de Badajoz, Jerez de la Frontera o Niebla ${ }^{15}$.

En un reciente artículo hemos atribuido tales diferencias a la necesidad que tuvo el poder almohade de legitimar su autoridad en al-Andalus, presentándose como sucesores de los califas omeyas. Así, para lograr sus objetivos políticos, las construcciones emblemáticas, tales como las puertas de las fortificaciones, debieron de asumir una serie de rasgos formales, realmente arcaizantes para la época en que se sitúan, que los relacionasen con los principios estéticos vigentes durante el período omeya en sus construcciones ${ }^{16}$. La utilización de la cantería, por ejemplo, será uno de ellos, en contraste con el predominio del ladrillo y la tabiya en el resto de elementos estructurales.

No obstante, en los territorios peninsulares y norteafricanos bajo la administración de los Unitarios se desarrolló una estética con elementos comunes cuyas diferencias más notables podrían achacarse a intencionalidades propagandísticas, como acabamos de referir,

II Esta sura consta de cuatro aleyas, de las que la tercera y parte de la segunda y cuarta corresponden con el fragmento desaparecido indicado entre corchetes.

12 Entre la bibliografía existente sobre el tema, destaca ÁLVAREZ GARCÍA, BUENDÍA MORENO, 2005, pp. 73 a 92.

I3 SOUTO LASALA, 2005, p. 160 a 162 aporta unas interesantes reflexiones sobre el valor simbólico del arco de herradura.

14 En la fachada primitiva de la puerta de Sevilla, en el recinto urbano de Niebla, subsisten porciones de la jabelga, presumiblemente original, sobre la que no parece haberse trazado motivo ornamental alguno. No obstante, hay que señalar que en las albanegas y rosca del Postigo de la Coracha y segundo arco de la Puerta del Capitel en la alcazaba de Badajoz y de la primitiva puerta del castillo de Fuengirola se conservan líneas incisas sobre el mortero original que simulan un aparejo más regular que el real. Semejante tratamiento tectónico se aprecia en zonas más periféricas del referido Postigo de la Coracha y de casi todas las portadas del recinto de Niebla. Esta decoración de simulacro de piezas escapa a la tradicional clasificación de motivos vegetales, geométricos y epigráficos.

15 Excepcionalmente, dos de las portadas del recinto de Niebla están rematadas por tríos de arcos lobulados ciegos.

I6MÁRQUEZ BUENO, S. y GURRIARÁN DAZA, P., Op. Cit, 2008. En el caso que nos ocupa, la presencia de la gran puerta exterior: como prolongación de la bóveda de cañón del corredor, recuerda a grandes portadas de época omeya como la que vemos en el alcázar de Calatrava la Vieja. Léase en RETUERCE VELASCO, HERVÁS HERRERA, 2002, p. 313. 
- a coyunturas específicas relacionadas con la acción y usos de constructores locales, y disponibilidad de recursos y materiales.

En cualquier caso, es muy probable que hacia finales de su dominio en al-Andalus, los almohades consideraran su poder lo suficientemente consolidado como para relajar sus postulados propagandísticos en materia de apropiación de referentes visuales de dinastías prestigiosas, y se hiciera más patente la influencia de la arquitectura militar emblemática desarrollada al otro lado del Estrecho. Este cambio de actitud se vería reflejado en la portada de Loja, en la que se combinan elementos de tradición almohade tanto andalusí como magrebí. Entre los primeros figura la concepción material y formal del arco, en la línea de puertas monumentales de cantería del último tercio del s. XII como las de la alcazaba de Badajoz, el castillo de Fuengirola o la Puerta de Sevilla en Carmona, por citar algunos ejemplos en los que el trazado geométrico es similar al de Loja, descrito en este mismo artículo. Entre los segundos, se podría incluir la proliferación de elementos de exorno con valor simbólico implícito, como la decoración de las albanegas y sobre todo la banda epigráfica. Como ya hemos mencionado, aunque las enjutas de las portadas almohades andalusíes no solían estar decoradas, a no ser que se considere el ornato de simulacro de piezas; existe otro ejemplo en Vejer de la Frontera que, al igual que Loja, tiene sus albanegas decoradas con atauriques (ABELLÁN PÉREZ, 1981; PAVÓN MALDONADO, 1999, pp. 506 y 507).

También en el interior de la torre se localiza un motivo ornamental de marcado carácter simbólico, propio de la arquitectura almohade, y generalizado a ambos lados del Estrecho desde la erección de la Giralda de Sevilla, que no es otro que la mencionada sebka que tapiza la bóveda de la estancia principal ${ }^{17}$.

\section{HACIA LO NAZARÍ}

En esta portada se localizan los más antiguos ejemplos conocidos de elementos decorativos, de patente valor simbólico, que harán fortuna en el posterior desarrollo de las puertas monumentales nazaríes. Nos estamos refiriendo a la llave y a la existencia de una banda de tipo epigráfico.

Nuestro caso estará, por tanto, en la línea formal de la serie de inscripciones monumentales de las puertas de Siete Suelos, Vino y Justicia, erigidas o reformadas a mediados del s. XIV en el recinto de la Alhambra de Granada. A pesar de estar documentada gráficamente en un grabado antiguo ${ }^{18}$, la inscripción de la primera no se conserva, por lo que únicamente se puede establecer una comparación efectiva entre las del Vino y Justicia con la de Loja (Láms. 7, 8 y 9). En las dos últimas, la banda epigráfica ocupa toda la anchura de la fachada en que se erige el arco monumental, y en los tres casos se inscribe en una cartela rectangular limitada en sus extremos por lazos, con forma de semicircunferencia, lobulados y anudados. Las similitudes continúan en detalles como los nudos cuadrangulares de los vértices del marco rectangular de las bandas, muy parecidos sobre todo entre Loja y Justicia. Lógicamente, las inscripciones alhambreñas muestran una ejecución técnica más compleja y unas formas más evolucionadas y estilizadas. Concretamente, mientras que la banda de Loja está ejecutada con yeso tallado, y originariamente policromada en blanco sobre fondo negro ${ }^{19}$, la del Vino también se talló en yeso, pero con mayor definición de detalles; $y$ la de la Puerta de la Justicia se labró en dos desiguales placas de mármol rellenándose la superficie rebajada con pasta vítrea azul. Por otra parte, la inscripción lojeña está trazada en cúfico florido un tanto tosco y las granadinas en cursiva finamente tallada.

17 Se recogen una interesantes reflexiones sobre la proliferación de este motivo ornamental en GURRIARÁN DAZA, 2000, pp. I77 y ss. 18 El grabado en cuestión es referido y reproducido en PAVÓN MALDONADO, 1995-1996, p. 40, y en Op. Cit., 1999 , pp. 457 y 467. 19 Dato técnico que agradecemos a la cortesía del arqueólogo Antonio Buendía Moreno. 
Donde sí se registran notables diferencias es en el contenido de las referidas bandas, pues como ya se refirió, el de Loja recoge una cita coránica totalmente en la línea de las inscripciones monumentales almohades norteafricanas; y por el contrario, el de la Puerta de la Justicia alude al sultán promotor de la obra y refleja la fecha de su erección, retomando una tradición asentada desde época omeya e interrumpida por las autoridades Unitarias.

En cuanto a la llave, se trata de una representación que figura en casi todas las puertas nazaríes, actualmente subsistentes, combinada de forma habitual con otros elementos simbólicos como la llamada mano de Fátima o el escudo de la Orden de la Banda. Tanto los ejemplares nazaríes como el tardoalmohade de Loja son iconográficamente idénticos, pues en todos ellos aparece la llave en posición vertical con la cabeza hacia arriba y de la que pende un cordón con borla. No obstante, las llaves nazaríes presentan un aspecto más depurado y estilizado, producto del asentamiento de la forma y generalización de su uso (Lám. 10). Incluso, ostentan una posición semánticamente más apropiada dentro de la portada, pues el caso de Loja es en el que dicho elemento se emplaza más lejos del arco de ingreso, por encima de la inscripción. Al contrario que en los casos nazaríes en los que se ubica en las proximidades del vano de la puerta, en la clave del propio arco o en la clave del dintel adovelado que generalmente se sitúa justo encima, y por debajo de la inscripción en caso de haberla.

A pesar de que el significado de este símbolo no está suficientemente aclarado, creemos que debe de relacionarse con una manifestación del poder de la dinastía que lo emplea 20. De modo que si bien es cierto que la llave, en su emplazamiento habitual, aparece a finales de época almohade, será bajo los nazaríes cuando se consolide su simbolismo convirtiéndose en uno de los elementos que conforme la identidad corporativa que identifica la producción arquitectónica militar de la dinastía granadina. En resumidas cuentas, y de vuelta al ejemplar objeto de estudio, la reflexión más sugerente que podemos aportar sería que, tanto por su forma como por su ubicación y la ausencia de precedentes conocidos, la llave de Loja podría constituir uno de los primeros casos conocidos de empleo de este símbolo en portadas monumentales de la arquitectura islámica occidental.

Al contrario que en la portada, donde se percibe una evidente unidad constructiva y sincronismo, la sala principal muestra elementos de diferente adscripción cronológica. De este modo, si bien la sebka de la cúpula orienta al encuadre del salón en período almohade, detalles como las granadas y racimos frutales ubicados en el arranque de las trompas nos llevan a suponerlos producto de una reforma de época nazarí o incluso cristiana.

\section{LA CONCEPCIÓN DEL ESPACIO}

Lo que no creemos que debió de sufrir cambios significativos a lo largo del período andalusí fue el uso de cada uno de los espacios en que se organizaba la torre. Así, hemos considerado tres zonas en que se pueden clasificar los distintos espacios de la torre según se les atribuyó una función representativa, militar o residencial.

La zona de representación del poder incluiría el espacio inmediato a la portada monumental, la sala con cúpula y quizás las alcobas laterales. La concepción formal y espacial de dicha sala respondería a la de una qubba entendida funcionalmente como "salón del trono" (MANZANO MARTOS, 1994), destinada a recepciones, administración de justicia y otros

20 La mayoría de los autores consultados recogen la presencia de la llave en las portadas nazaríes, pero eluden cualquier referencia a posibles contenidos simbólicos. Entre los que aportan algún dato, en GRABAR, O., La Alhambra: iconografía, formas y valores, Madrid, 1980, p. 43. se reconoce que su significado no está suficientemente aclarado; se afirma que se trata de un talismán en TORRES BALBÁS, 1949, p. 86, y se relaciona con un símbolo de poder en VILLA-REAL MOLINA, 1979, p. I I3. Resulta Ilamativo cómo el autor de la publicación menos especializada de las consultadas es el que, a nuestro juicio, realiza la reflexión más acertada. 
actos entre los que simbolizaban el poder y los que eran objeto de su acción y presencia. En resumen, la zona de representación constituiría un marco escenográfico en el que se desarrollaban todas las actividades y actos en los que se hacían visibles los atributos del poder de la clase gobernante.

De la zona militar, compuesta por aquellas estancias destinadas a la defensa y guarnición de la torre, actualmente sólo puede identificarse el espacio dispuesto sobre la bóveda de cañón, que cubre el espacio previo a la puerta monumental, gracias a su buhedera. Es probable que la altura de los habitáculos que conformasen este sector coincidiera con la elevación de la clave de la cúpula de la qubba, de modo que por encima se ubicase el hipotético espacio residencial (Fig. 5).

Podría considerarse la reunión de las mencionadas funciones en una gran torre como una clara influencia de las de homenaje de las fortalezas cristianas, que comenzó a hacerse patente a finales de época almohade en el levante andalusí ${ }^{2}$. A pesar de que la tendencia a erigir grandes torres se consolidó en el Reino de Granada, solamente es posible asegurarles un uso militar y residencial. Sin embargo, sería posible ver un paralelo al caso de Loja en la llamada Torre de Homenaje de la alcazaba de la Alhambra. Su construcción se enmarca en los primeros años de la dinastía nazarí y se le reconoce un uso residencial y protocolario, al margen del militar implícito (MALPICA CUELLO, 2007, p. 77).

Pero en ningún caso la función representativa se manifiesta tan evidente como en Loja; pues la torre que nos ocupa es la única conocida bajomedieval en la que el arco de ingreso adquiere una forma y dimensiones propias de accesos a recintos urbanos y alcazabas, nunca visto antes en torres o calahorras, con independencia de su tamaño ${ }^{22}$. El ejemplo más claro que podemos referir, mucho más antiguo, sería el de la primitiva Torre del Homenaje de la Alcazaba de Málaga, obra del siglo XI. Se trata de un gran volumen paralelepipédico, en el que se abría en su origen un gran arco monumental tras el cual se situaba el califa hammudí, según una tesis esgrimida por el profesor Acién Almansa (Lám. II) 23. Con posterioridad este arco áulico sería cegado, una vez perdida su finalidad representativa en periodo almohade.

\section{CONCLUSIONES}

La llamada Torre del Homenaje de la alcazaba de Loja constituye el más claro eslabón conocido entre la arquitectura militar almohade y nazarí, ejecutada en esos años de transición que median entre la descomposición final del poder africano y su sustitución por las nuevas dinastías locales. Difícil de encuadrar con exactitud según los datos disponibles, esta obra bebe de las principales características de la arquitectura de ambos momentos, ya madura la almohade y aún por definir la granadina. En efecto, si bien se sitúa en los últimos años del dominio de los Unitarios en la Península, en ella aparecen ya rasgos formales y simbólicos que luego perdurarán en la imagen corporativa de la arquitectura monumental nazarí, y que se desarrollarán hasta sus últimas consecuencias en la gran ciudad palatina de los últimos siglos de al-Andalus: La Alhambra.

Desde un punto de vista material, la torre estudiada es el resultado de una intervención

2 I Léase en AZUAR RUIZ, 2005, acerca de la Torre del Homenaje del castillo de Villena. Sobre las grandes torres de la arquitectura militar andalusí se puede consultar PAVÓN MALDONADO, 1999, pp. 31 I a 340.

22 La más grande de las calahorras andalusíes, la de Gibraltar, erigida en la cuarta década del s. XIV, poseyó un acceso discreto; y si bien alguna de sus estancias pudo tener un uso protocolario, quizás la que ostenta una estrella de ocho puntas en su clave, ninguna de ellas tiene un desarrollo volumétrico que le confiera especial preponderancia sobre las demás. Consúltese TORRES BALBÁS, I942, pp. 60 a 116.

23 Este arco sería un reflejo de los que forman la gran arquería oriental del alcázar de Madinat al-Zahra'. ACIÉN ALMANSA, I999a, pp. 173 a 204, especialmente p. 189. El mismo autor insiste en esta teoría en LÓPEZ GUZMÁN (Coord.), 1995, p. 37. 
constructiva en sillería, de tipo unitario, que sufre algunos apaños posteriores. La obra llegó desmochada a la Edad Moderna, recreciéndose finalmente con piezas de acarreo y aparejo irregular en un momento indeterminado. La técnica original es extraña a la edilicia bajomedieval lojeña, y podría hablar de la importancia de este encargo, que incluso conllevó el recurso a canteros sólo para esta construcción. No obstante, se ha de incidir en la relación existente con la práctica almohade en al-Andalus de ejecutar sus puertas monumentales con cantería, reservando dicha técnica a estos puntos nobles, en los que se prescindía de materiales menos cuidados pero comunes como hormigones o ladrillos, que sí aparecían en el resto de las defensas. En Loja se seguiría esta costumbre que vemos en las puertas de tantos recintos andalusíes almohades, y por tanto, no se trataría de una situación excepcional.

Llama la atención, por último, el carácter representativo de esta obra oficial que, en definitiva, se erige en una plaza "secundaria". La carga de simbolismo de epigrafía y ornatos queda superada por el propio carácter funcional de la torre: un gran cuerpo abovedado donde el representante de la autoridad se manifiesta detrás de una puerta monumental. El paralelo taifa de la alcazaba de Málaga es evidente, si bien la comparación entre un califa que se consideraba heredero de los omeyas y el gobernador de un recinto sin demasiada significación, pone en evidencia que el concepto de manifestar el poder a través de estas torres singulares estaba arraigado en el mundo andalusí, con independencia del periodo que consideremos y del emplazamiento de la obra.

\section{BIBLIOGRAFÍA}

ABELLÁN PÉREZ, J. (198I): "La puerta musulmana del castillo de Vejer de la Frontera", Estudios de Historia y Arqueología Medievales, I, Cádiz.

ACIÉN ALMANSA, M. (1995a): "La fortificación en alAndalus", Archeologia Medievale, XII, pp. 7 a 36.

ACIÉN ALMANSA, M. (1995b): "La fortificación en alAndalus" en LÓPEZ GUZMÁN, R. (coord.) La arquitectura del Islam occidental, Barcelona, pp. 29 a 4l.
ACIÉN ALMANSA, M. (1999a): "La torre del homenaje de la Alcazaba de Málaga: secuencia, estratigrafía, medición e interpretación", Arqueología del monumento: Terceros Encuentros de Arqueología y Patrimonio, Salobreña, del 13 al 16 de octubre de 1992, Salobreña, pp. 173 a 204.

ACIÉN ALMANSA, M. (1999b): "Los tugur del Reino Nazarí. Ensayo de identificación", Castrum 5. Archéologie des espaces agraires méditerranéens au Moyen Âge, Collection de la Casa de Velázquez, 55, Murcia, pp. 427 a 438.

AL-HIMYARI (1938): La péninsule ibérique au Moyen Age d'après le Kitāb ar-Rawd al-Mi'tār, Trad. Lévi-Provençal, E., Leiden.

ÁLVAREZ GARCÍA, J. J. y BUENDÍA MORENO, A. F. (2005): "La Alcazaba de Loja. Fases de actuación desde la perspectiva de una intervención integral", Los Castillos. Reflexiones ante el reto de su conservación. Actas de las Jornadas, Alcalá la Real 26-28 de mayo de 2004, Sevilla, pp. 73 a 92.

AZUAR RUIZ, R. (2004): "Técnicas constructivas y fortificación almohade en al-Andalus", Los almohades: su patrimonio arquitectónico y arqueológico en el sur de al-Andalus, Sevilla, pp. 57 a 74.

AZUAR RUIZ, R. (2005): "Aspectos simbólicos de la arquitectura militar almohade. El falso despiece de sillería y las bóvedas de arcos entrecruzados", Los almohades: problemas y perspectivas, Tomo I, Estudios Árabes e Islámicos, Monografías $N^{\circ}$ I I, Madrid, pp. 123 a 147.

GRABAR, O. (1980): La Alhambra: iconografía, formas y valores, Madrid, .

GURRIARÁN DAZA, P. (2000):"Acerca del alminar almohade de Cuatrovitas en Bollullos de la Mitación", Caetaria, $N^{\circ}$ 3, Algeciras, pp. 177 y ss.

GURRIARÁN DAZA, P. y SÁEZ RODRÍGUEZ, A. J. (2002): "Tapial o fábricas encofradas en recintos urbanos andalusíes", Actas del II Congreso Internacional "La Ciudad en al-Andalus y el Magreb" (Algeciras, noviembre 1999), Granada, pp. 561 a 625.

GURRIARÁN DAZA, P. (2000): "Arquitectura y técnicas constructivas en al-Andalus durante la época almohade", Historia de las técnicas constructivas en España, Madrid.

JIMÉNEZ PUERTAS, M. (1995): "El poblamiento rural de la tierra de Loja a fines de la Edad Media", Arqueología y Territorio Medieval, 2, pp. 63 a 82.

MALPICA CUELLO, A. (1996): Poblamiento y castillos en Granada.

MALPICA CUELLO, A. (1998): "Los castillos en época nazarí. Una primera aproximación", Castillos y territorio en al-Andalus (Berja, 1996), Granada, pp. 246 a 293.

MALPICA CUELLO,A. (2007): La Alhambra, ciudad palatina nazarí, Málaga.

MANZANO MARTOS, R. (1994): La Qubba, aula regia en la España musulmana, Madrid.

MÁRQUEZ BUENO, S. y GURRIARÁN DAZA, P. (2008): "Recursos formales y constructivos en la arquitectura militar almohade en al-Andalus", Arqueología de la Arquitectura, número 5, Madrid, pp. II 5 a 134. 
MARTÍNEZ NÚÑEZ, M.A. (1997):"Epigrafía y propaganda almohades", Al-Qantara XVIII, Madrid, pp. 4 I 5 a 446.

MARTíNEZ NÚÑEZ, M. A. (2005): "Ideología y epigrafía almohades", Los almohades: problemas y perspectivas, Tomo I, Estudios Árabes e Islámicos, Monografías № I I, Madrid, pp. 5 a 52.

PAVÓN MALDONADO, B. (1995-1996): "La Puerta del Vino de la Alhambra y el arte almohade de España y norte de áfrica", Cuadernos de la Alhambra, Vol. 31-32, Granada, pp. 15 a 92.

PAVÓN MALDONADO, B. (1999): Tratado de arquitectura hispano-musulmana II, Madrid.

QUIRÓS CASTILLO, J.A. (1998): “La sillería y las técnicas constructivas medievales: historia social y técnica de la producción arquitectónica", Archeologia Medievale, XXV, pp. 235 a 246.
RETUERCE VELASCO, M. y HERVÁS HERRERA, M. A (2002): "Calatrava la Vieja. De medina a encomienda", Mil anos de Fortificaçoes na Península Ibérica e no Magreb, Palmela, pp. 31 I a 317.

SÁNCHEZ MARTíNEZ, J. A. et alii (1994): El barrio de la Alcazaba de Loja. Historia de una ciudad, Barcelona.

SOUTO LASALA, J. A. (2005): El conjunto fortificado islámico de Calatayud, Zaragoza.

TORRES BALBÁS, L. (1949): Ars Hispaniae, tomo IV, Madrid.

VILLA-REAL MOLINA, R. (1979): La Alhambra y el Generalife, Granada. 


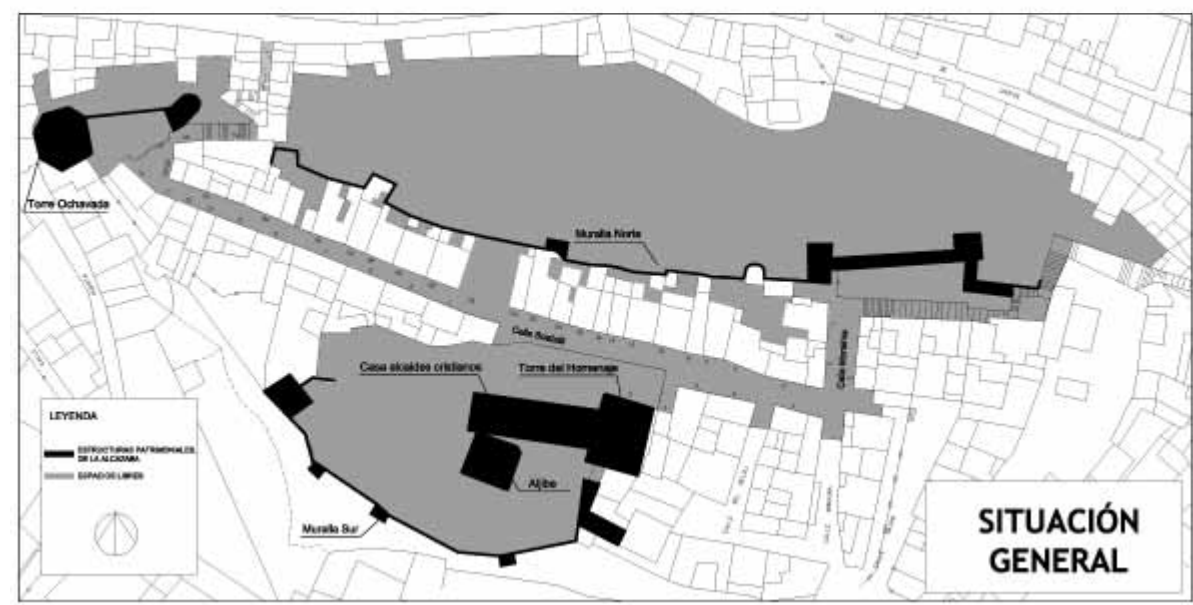

Fig. I. Planta general de la alcazaba de Loja con la situación de las construcciones patrimoniales conservadas (E //500 en el original)

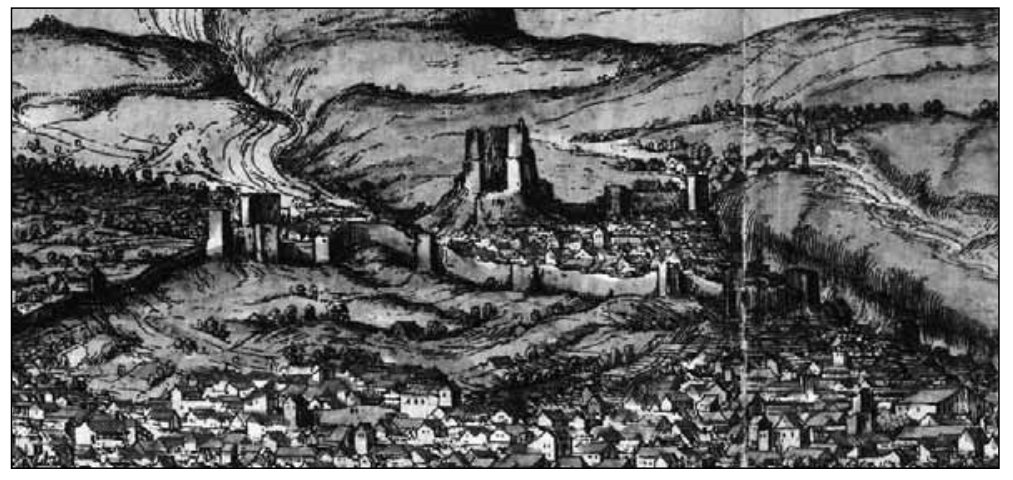

Fig. 2. Vista general de Loja desde el norte, en la que destaca el volumen de la Torre del Homenaje dominando el conjunto. Braun y Hogenberg, Civitates Orbis Terrarum, map II-7, 1575.

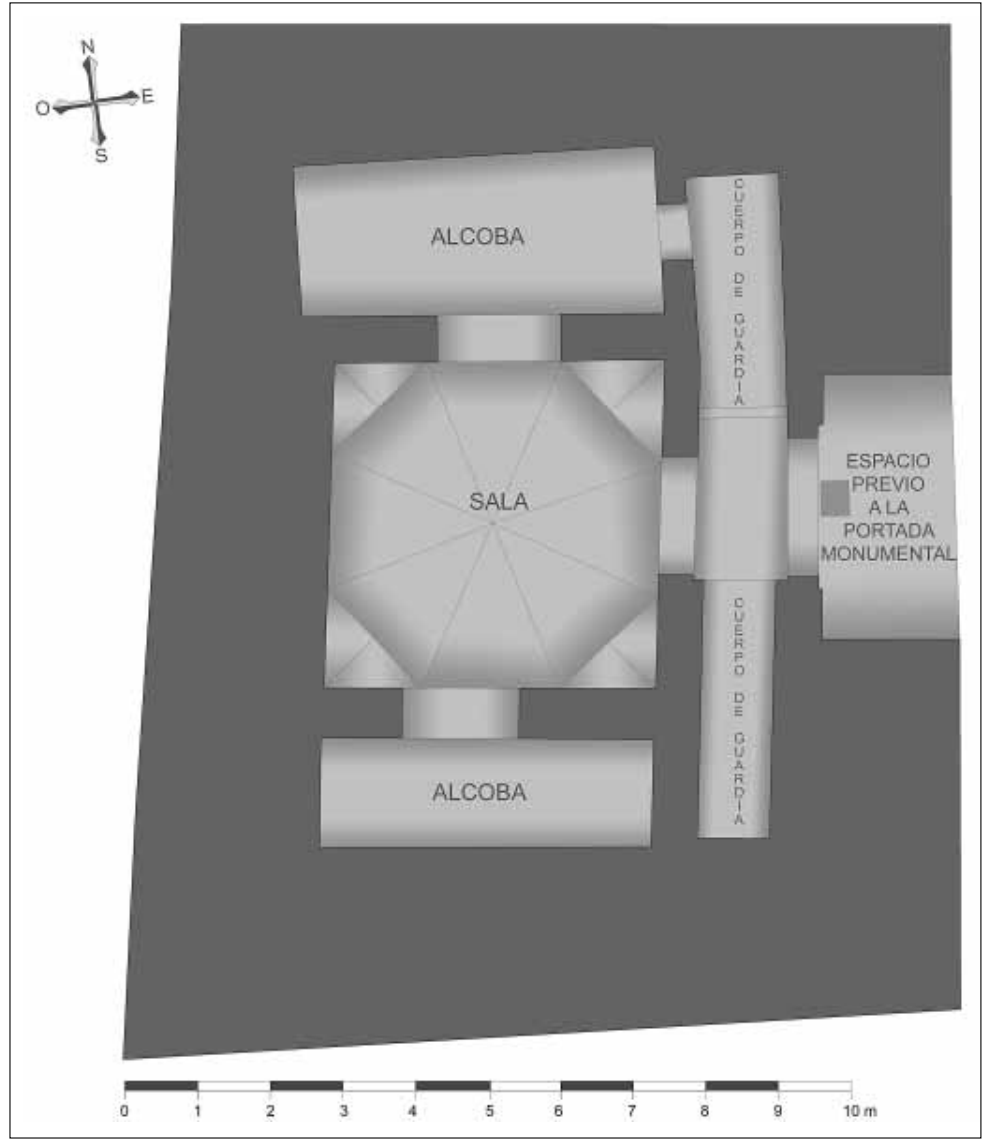

Fig. 3. Esquema general de la planta baja de la Torre del Homenaje de la alcazaba de Loja con la distribución original de las estancias y espacios. 


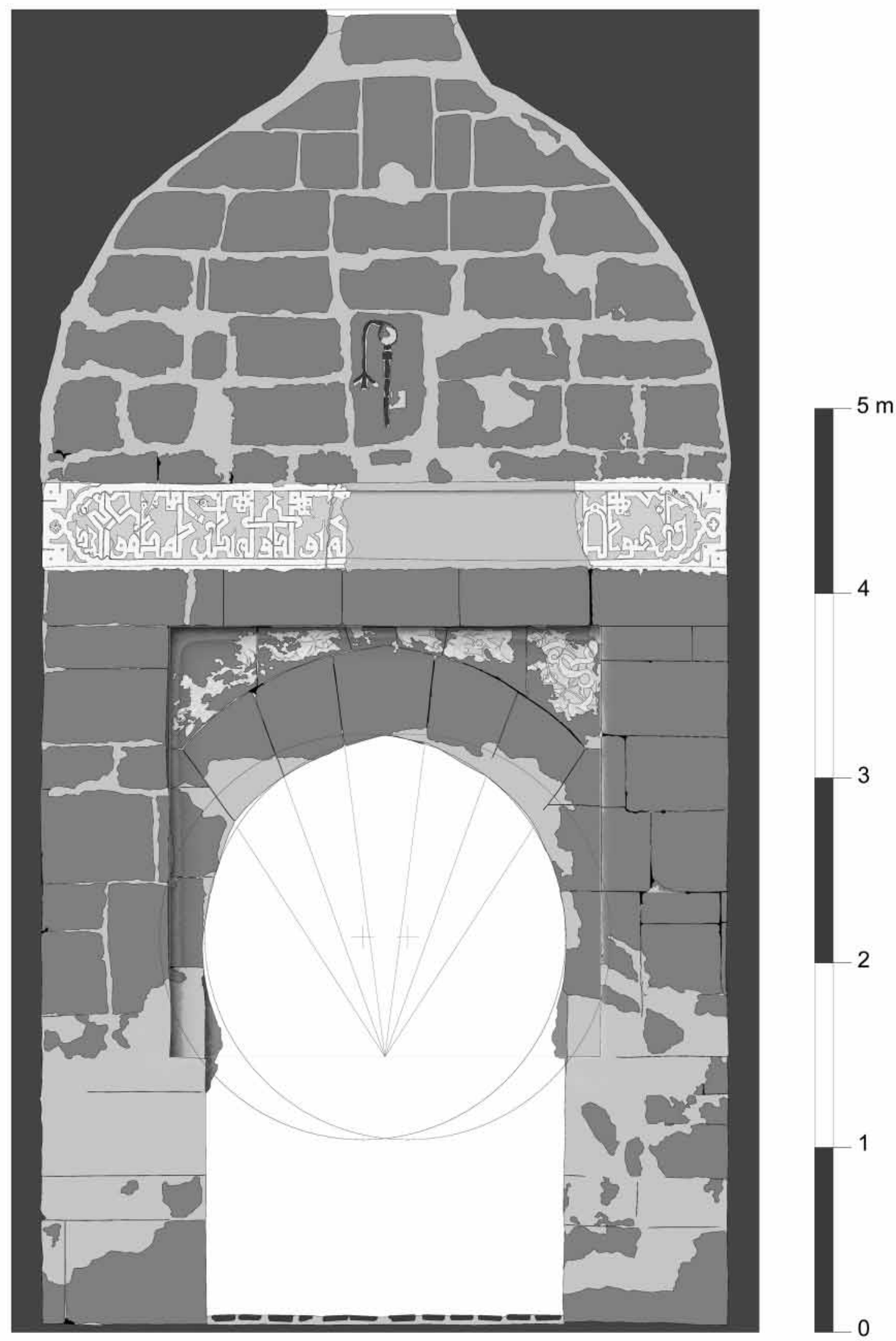

Fig. 4. Alzado fotogramétrico de la puerta de acceso de la Torre del Homenaje de la alcazaba de Loja (2008). 
Fig. 5. Restitución volumétrica ideal del estado original de la Torre del Homenaje de la alcazaba de Loja.
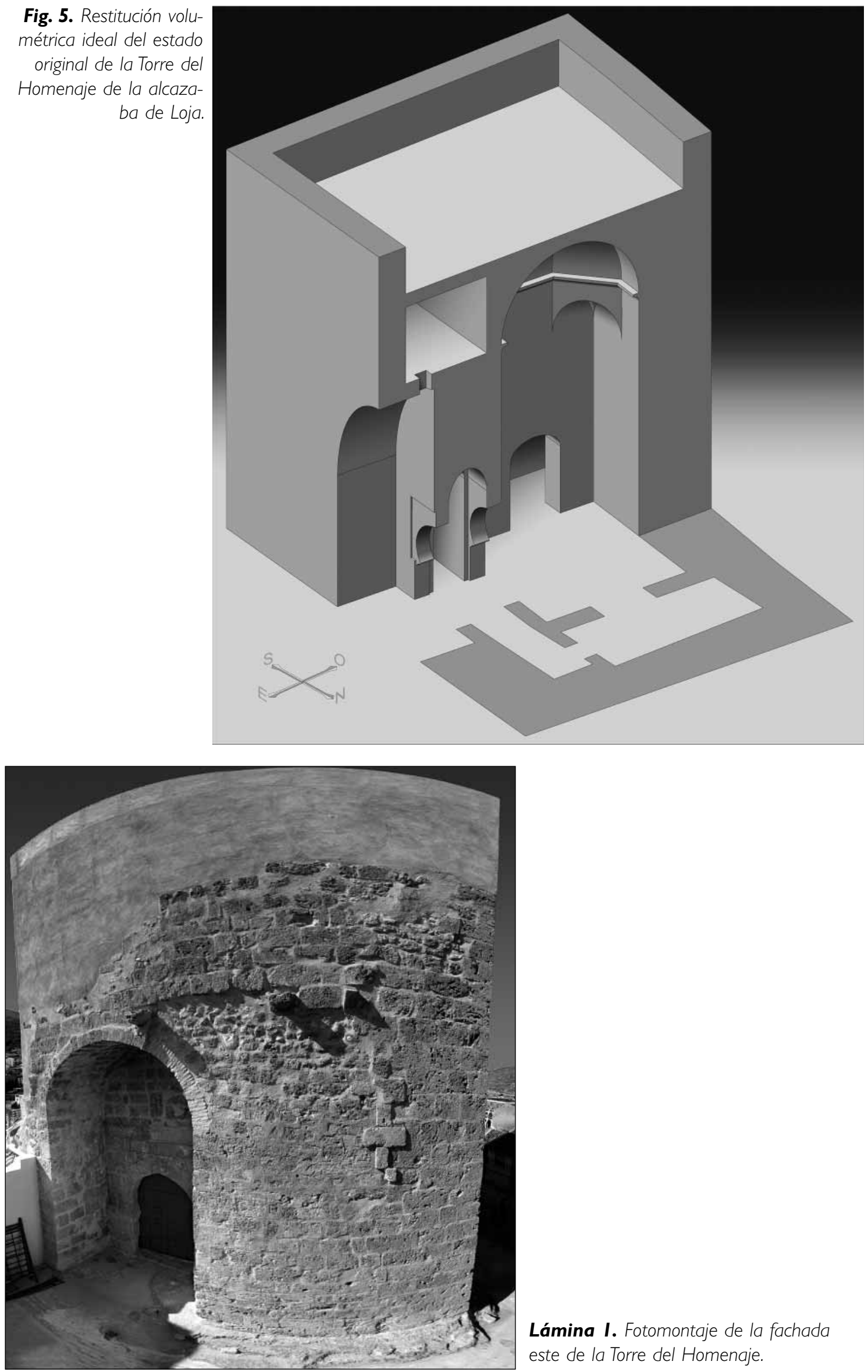

Lámina I. Fotomontaje de la fachada este de la Torre del Homenaje. 
Lámina 2. Decoración de las albanegas de la puerta de acceso de la Torre del Homenaje de la alcazaba de Loja.

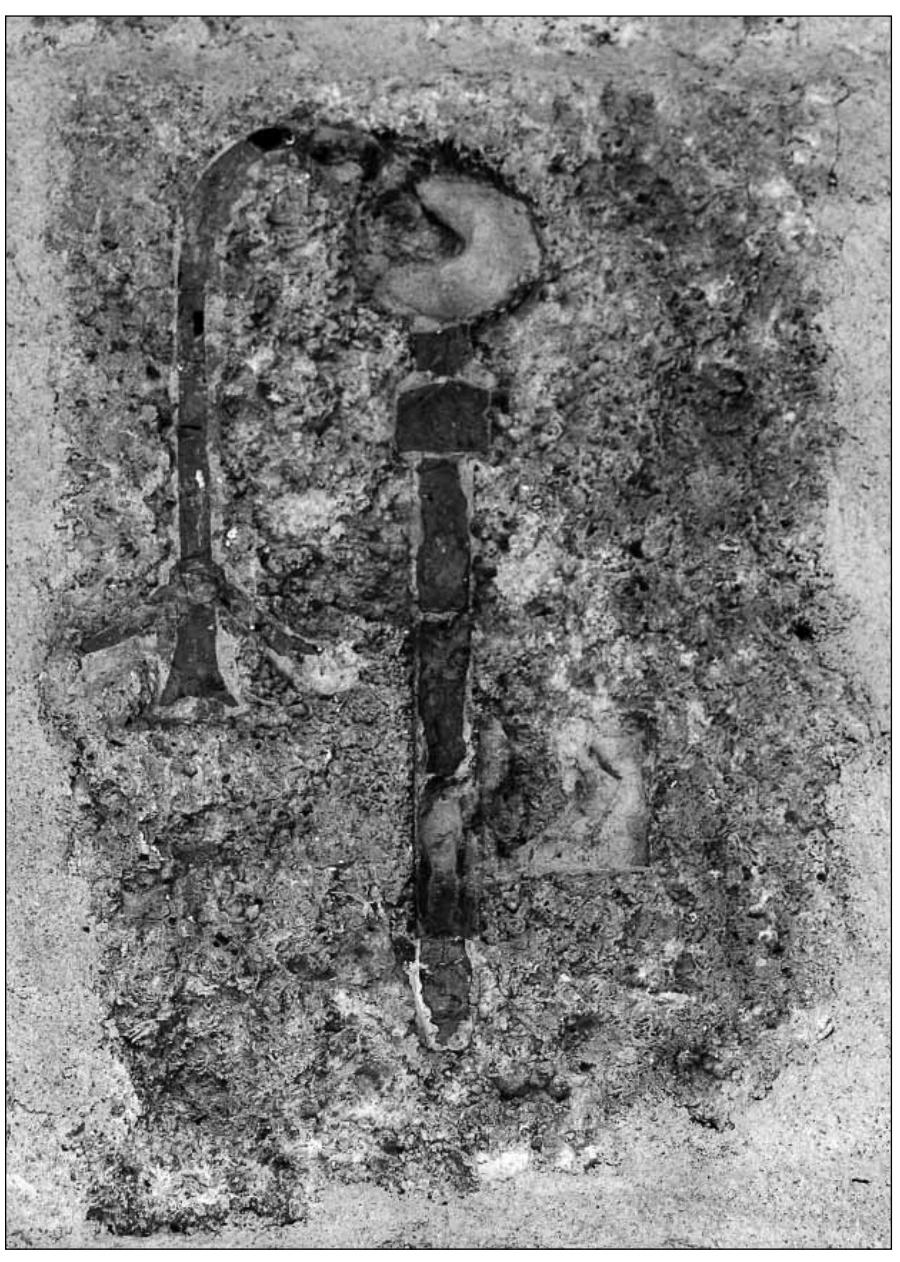

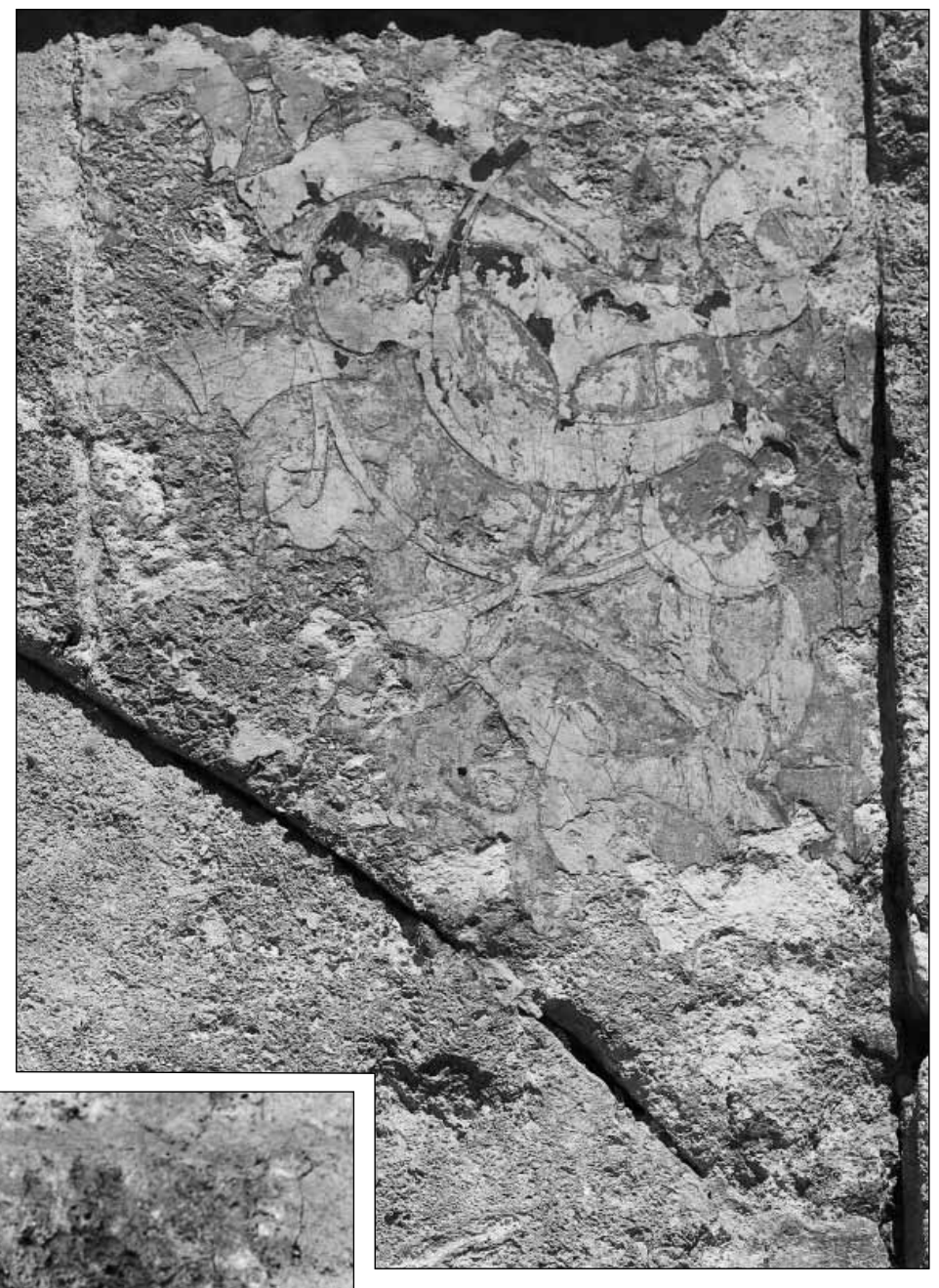

Lámina 3. Detalle de la llave situada sobre la puerta de acceso de la Torre del Homenaje de la alcazaba de Loja. 


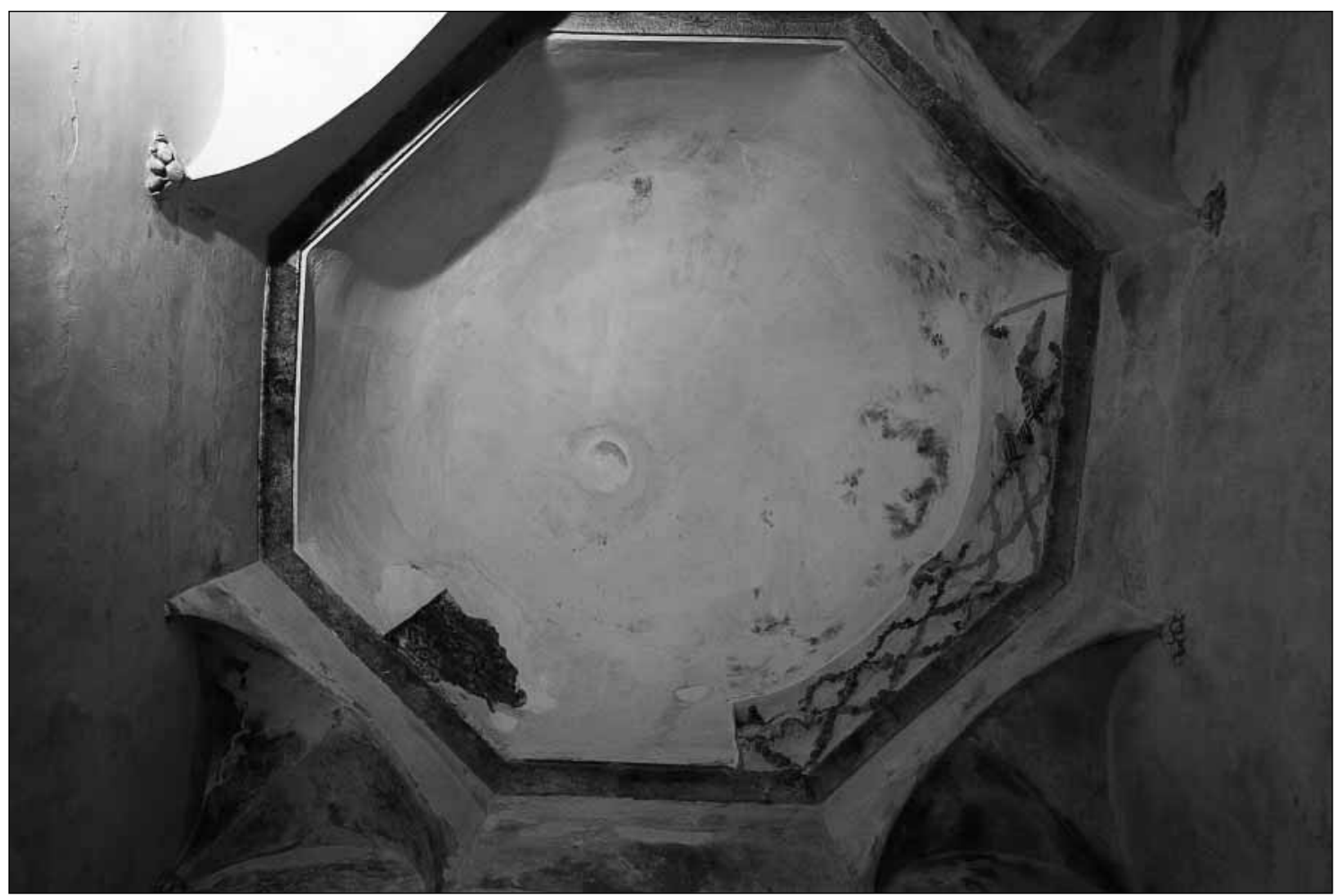

Lámina 4. Vista general de la bóveda de cubrición del espacio principal de la torre.

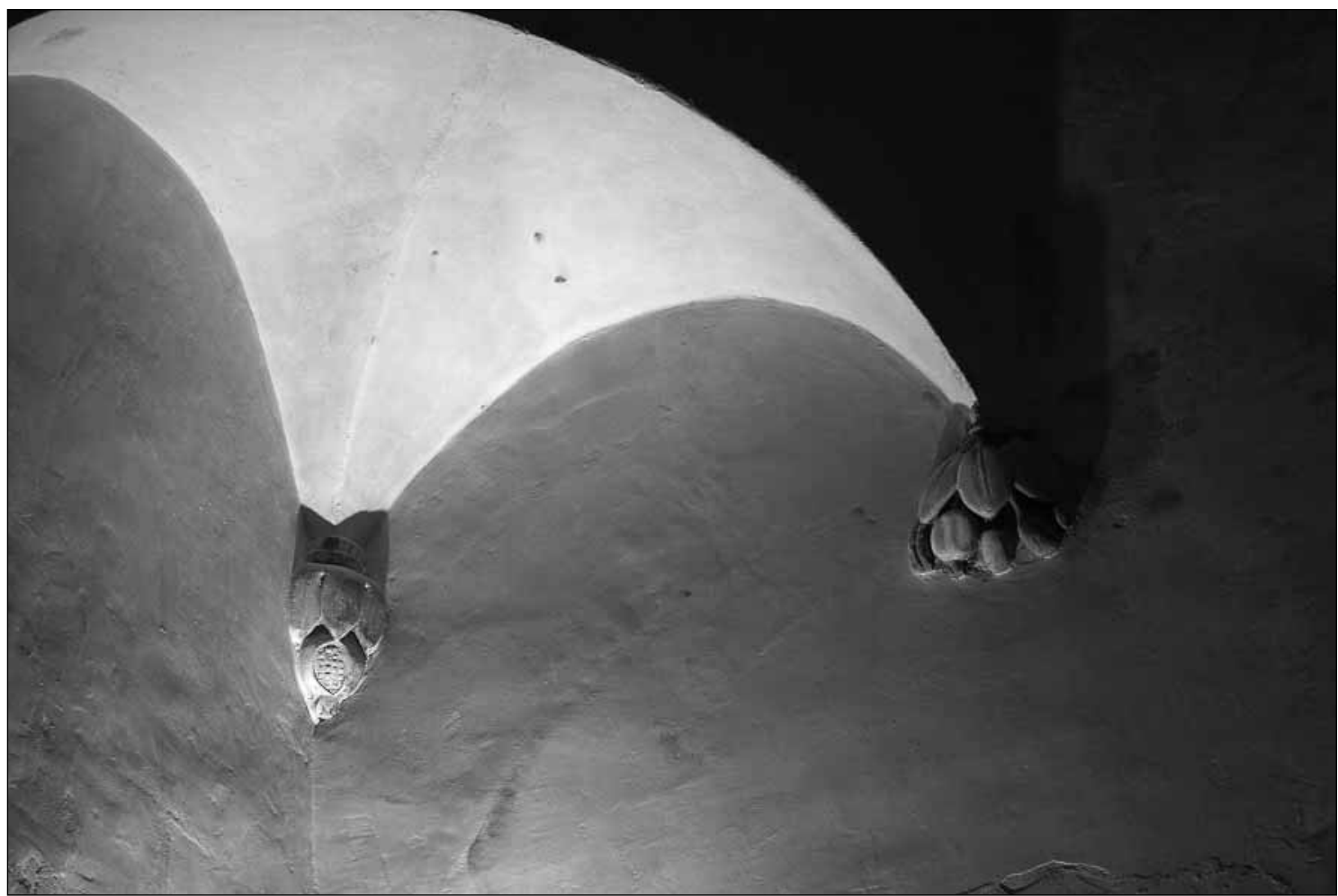

Lámina 5. Detalle de los motivos decorativos de la bóveda del espacio central de la Torre del Homenaje. 


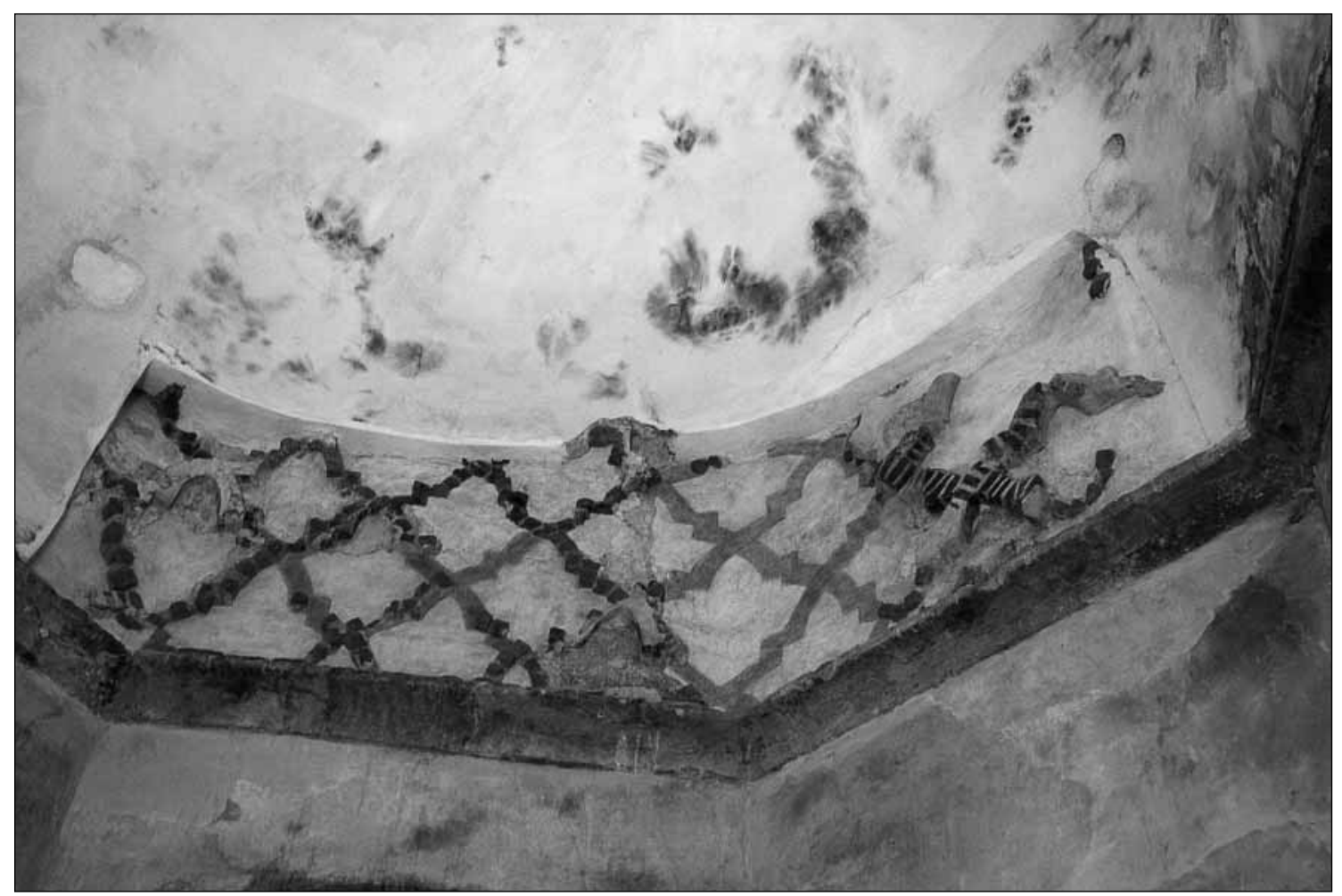

Lámina 6. Detalle de la decoración de entrelazo o sebka de los paños de la bóveda principal.

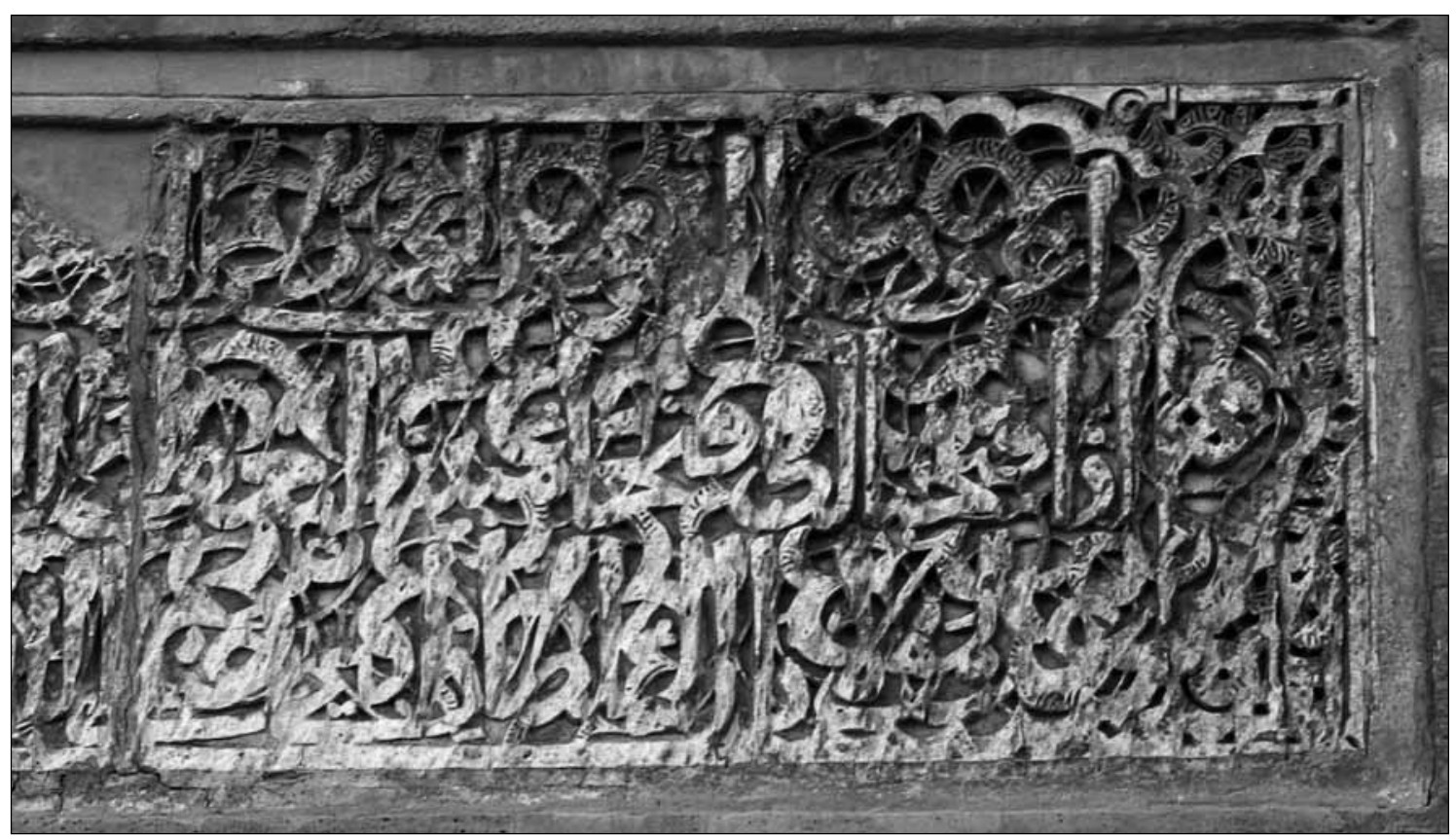

Lámina 7. Detalle del friso epigráfico que se sitúa sobre la fachada exterior de la Puerta del Vino de la Alhambra. 


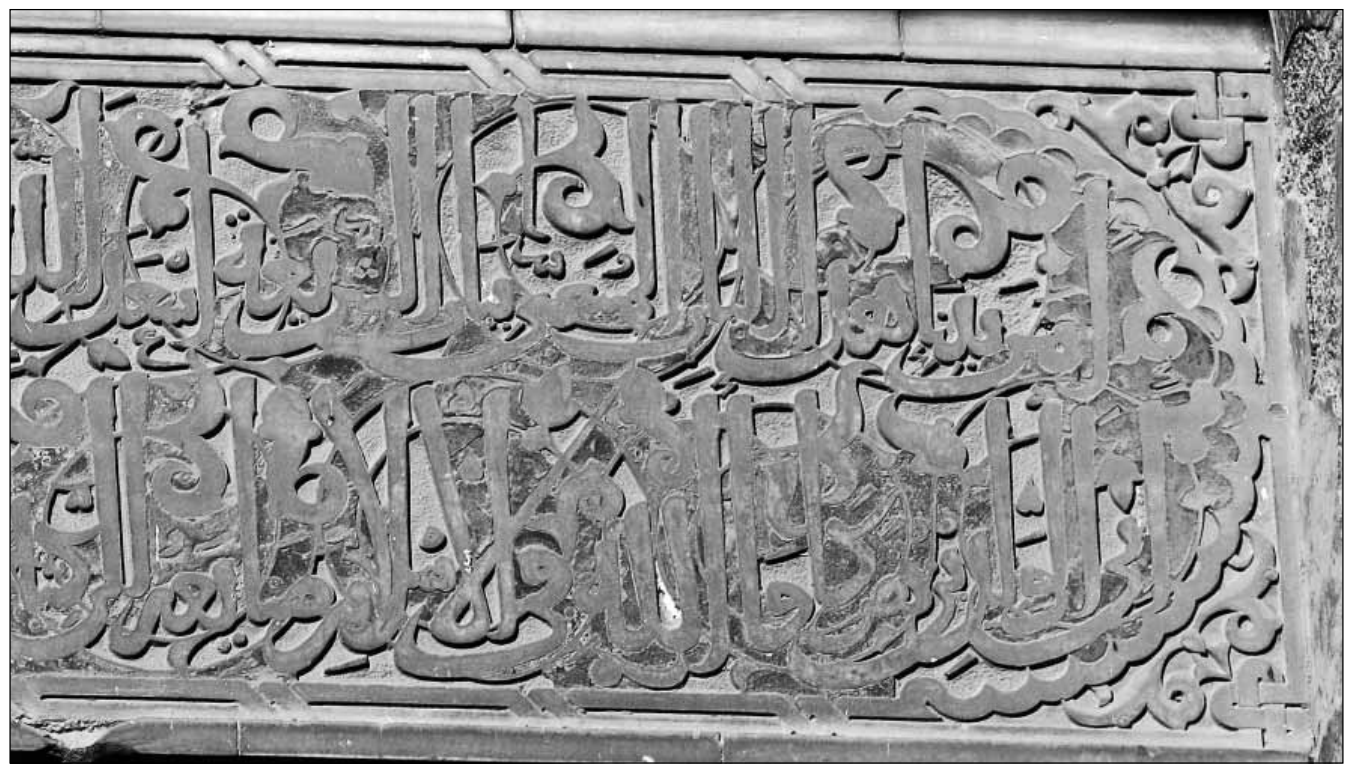

Lámina 8. Detalle del friso epigráfico que se sitúa sobre la fachada exterior de la Puerta de la Justicia de la Alhambra.

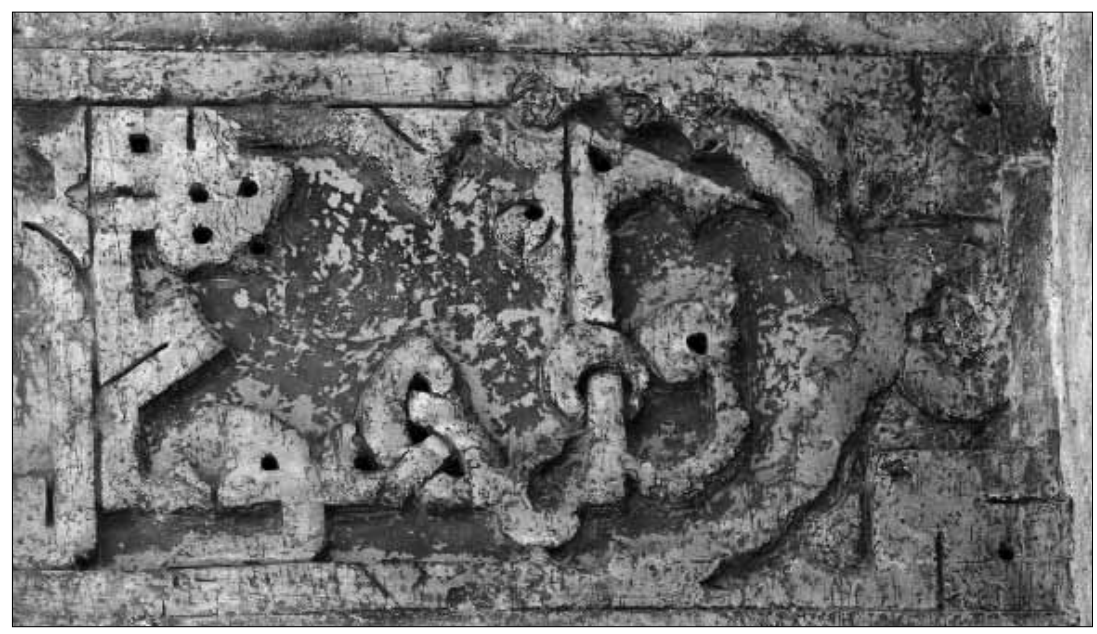

Lámina 9. Detalle del

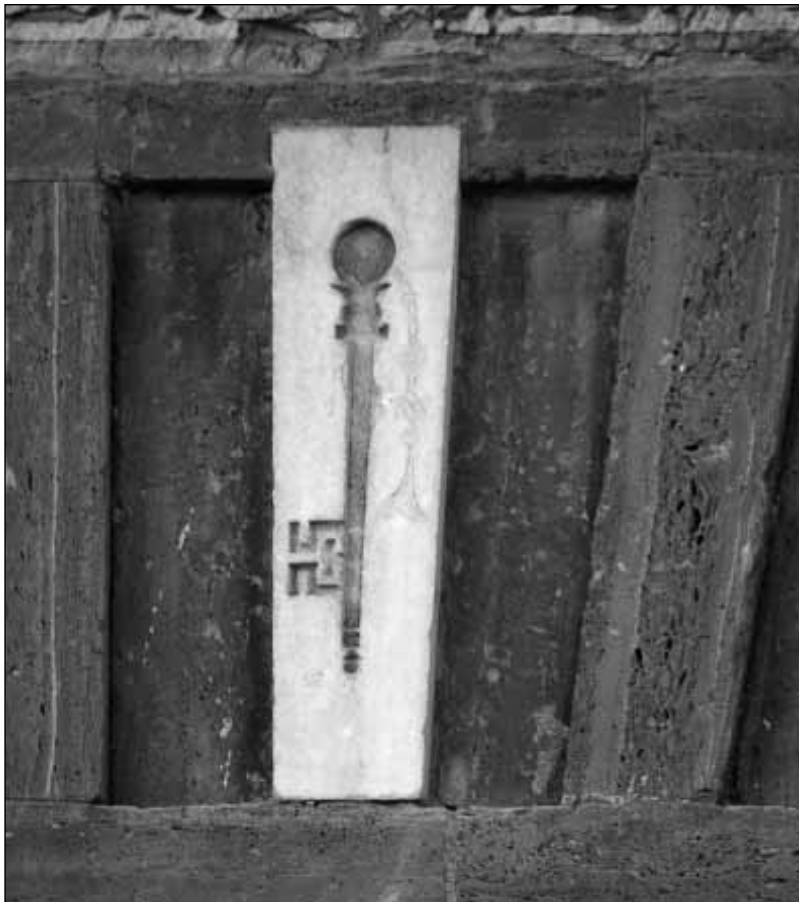

friso epigráfico conservado en la Torre del Homenaje de la alcazaba de Loja.
Lámina I0. Detalle de la llave que domina el arco del frente exterior de la Puerta del Vino de la Alhambra. 
Lámina I I. Vista general del frente norte de la Torre del Homenaje de la alcazaba de Málaga con el gran arco taifa cegado.

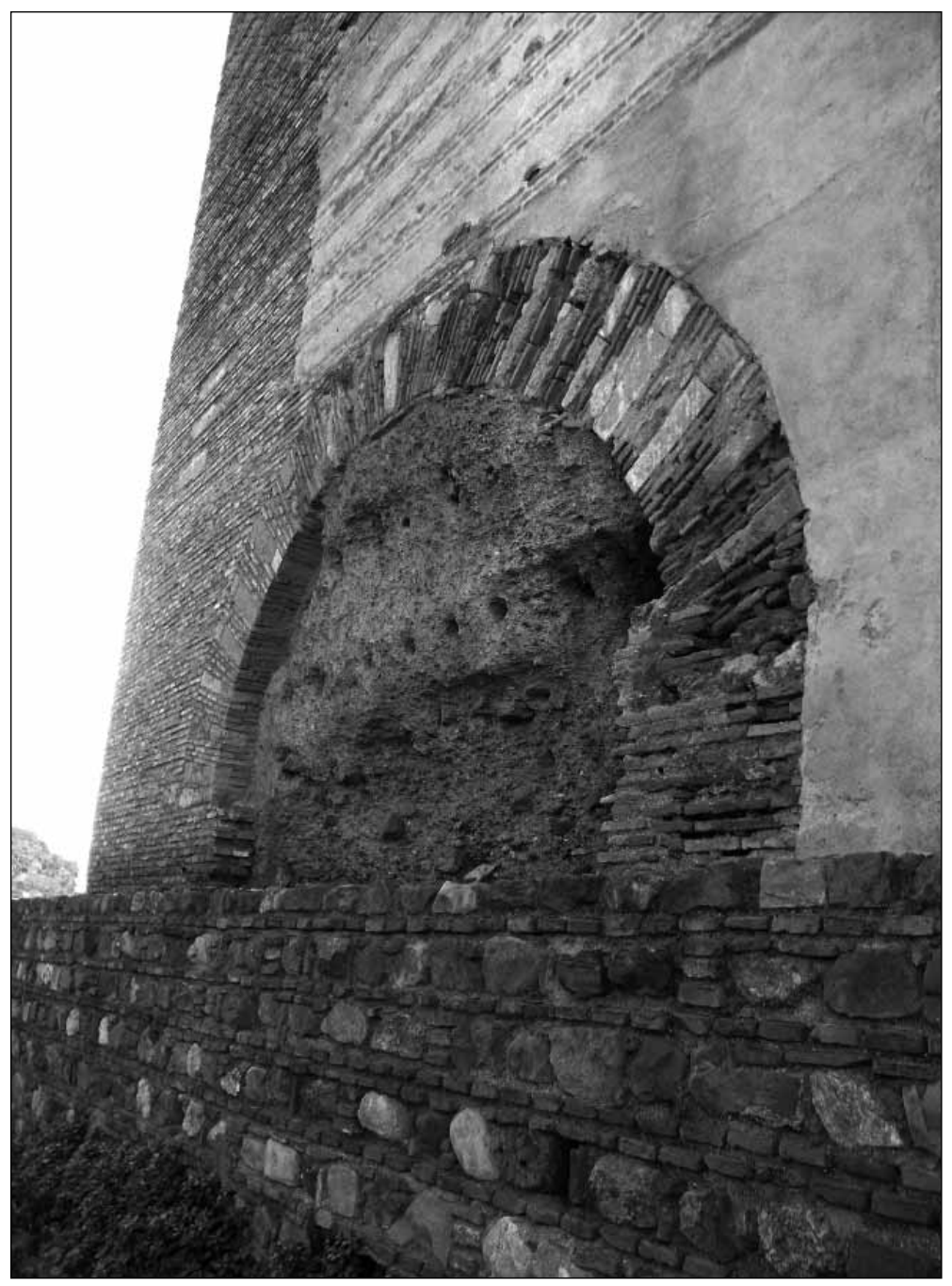

